\title{
SOLOS RESIDUAIS ARENOSOS DESENVOLVIDOS SOBRE OS SEDIMENTOS DO GRUPO ITARARÉ: ANÁLISE DE SUA CONDUTIVIDADE HIDRÁULICA NO ESTADO NATURAL E DETERMINAÇÃO DE SEUS PARÂMETROS GEOTÉCNICOS QUANDO COMPACTADOS.
}

\section{Daniel Luís Mantovani Marsura*, David de Carvalho.}

\section{Resumo}

O crescimento indiscriminado de áreas impermeáveis, impede a infiltração das águas pluviais, contribuindo para a ocorrência dos alagamentos e enxurradas. A partir de rochas arenosas atribuídas ao Grupo Itararé na região da cidade de Campinas - SP foi caracterizada a condutividade hidráulica deste tipo de solo para que haja dimensionamento de dispositivos de infiltração e drenagem a fim de reduzir estes problemas.

\section{Palavras-chave:}

Grupo Itararé, Condutividade Hidráulica, Parâmetro Geotécnico.

\section{Introdução}

A falta de planejamento urbano tem gerado, em cidades de todo o país, uma série de problemas, dentre os quais os alagamentos e as enxurradas estão entre os mais graves e recorrentes. O crescimento indiscriminado de áreas impermeáveis, constituídas por telhados e pavimentos, impede a infiltração das águas pluviais. Nestas áreas o volume de água infiltrada durante um evento de chuva é mínimo e praticamente toda a água precipitada transforma-se em escoamento superficial, o que contribui para a ocorrência dos alagamentos e enxurradas.

No geral os sistemas de drenagem urbana carecem de dispositivos que permitam a redução do volume de água escoado superficialmente e que evitem, ou reduzam, a sobrecarga dos dispositivos de condução das águas já implantados. A construção de poços e trincheiras de infiltração, pavimentos permeáveis, jardins de infiltração, entre outros dispositivos, em lotes urbanos são medidas de controle do escoamento na fonte geradora que apresentam uma mudança na filosofia de projeto e que contribuem para uma solução mais harmônica dos problemas discutidos anteriormente (Peixoto, 2011).

O objetivo geral desta pesquisa de iniciação científica é contribuir para a caracterização da condutividade hidráulica dos solos de alteração desenvolvidos a partir das rochas arenosas atribuídas ao Grupo Itararé na região da cidade de Campinas - SP.

\section{Resultados e Discussão}

Em uma área plana, próxima a um talude de exposição de solos de alteração de arenitos ou diamictitos do Grupo Itararé na região de Campinas - SP, foi realizado o ensaio de infiltração e determinação da curva de velocidade de infiltração da água, utilizando-se o método do infiltrômetro de anel, que consiste em dois anéis, colocados concentricamente.

A partir dos dados obtidos foi possível determinar a infiltração acumulada, a velocidade de infiltração básica e a sua curva de velocidade de infiltração da água no solo.

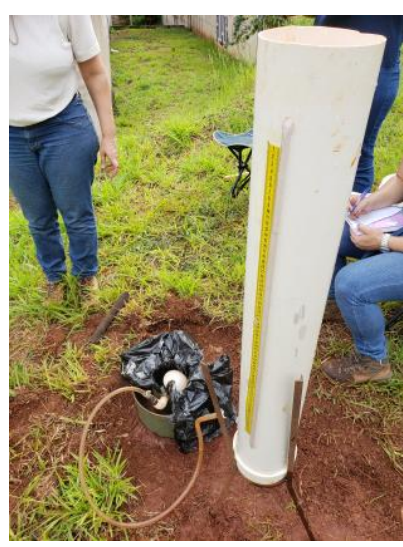

Figura 1. Método do infiltrômetro de anel

\section{Conclusões}

Diante dos dados do ensaio realizado, foi possível caracterizar que o solo possui uma alta velocidade de infiltração e consequentemente uma boa drenagem. Esse relatório se apresenta como final, pois houve 0 cancelamento da bolsa PIBIC/SAE em dezembro de 2018, como informado na vigência e, portanto, todos seus objetivos não foram alcançados (seguidos conforme 0 cronograma do projeto) e por isso seus resultados, discussões e conclusão são escassos.

\section{Agradecimentos}

Agradecimentos ao SAE/AF-UNICAMP que financiou este projeto, ao meu orientador Prof. Dr. David de Carvalho pelo apoio e incentivo oferecidos no decorrer desta pesquisa e à Faculdade de Engenharia Agrícola (FEAGRI) por todo apoio logístico e uso dos laboratórios.

ABNT NBR 6457/86 Amostras de Solos - Preparação para Ensaios de Compactação e Ensaios de Caracterização.

ABNT NBR 13292/95 Solo: determinação do coeficiente de permeabilidade de solos granulares à carga constante - Método de ensaio. Rio de Janeiro, 8p.

Basso, J.B. Migração de $\mathrm{K}+, \mathrm{Cu} 2+$ e $\mathrm{Cl}$ - em solos do subgrupo Itararé no estado de São Paulo: ensaios sorcivos, percolação em colunas e simulações geoquímicas. Universidade Estadual Paulista Júlio de Mesquita Filho: Rio Claro. 189 p, 2010

Peixoto, V.C. (2011) Análise paramétrica e dimensionamento de poços de infiltração para fins de drenagem urbana. Dissertação de mestrado. Escola de Engenharia de São Carlos: São Carlos. 111p. 